\section{MEDICAL IMPLICATIONS OF ULTRA MARATHON RUNNING: OBSERVATIONS ON A SIX DAY TRACK RACE}

\author{
M. A. HUTSON, MA, MB, BChir(Cantab), DObstRCOG \\ Sports Injury Clinic, General Hospital, Nottingham
}

\begin{abstract}
Medical records were kept of the injuries and illnesses sustained by competitors in a six day running race held in Nottingham in August 1982. The overall rate of injuries sufficiently severe to affect running performance was 60 per cent. These injuries are itemised and discussed with particular reference to the problems raised by this ultra distance race.
\end{abstract}

\section{INTRODUCTION}

The second Charles Rowell Six Day Race took place at the Harvey Hadden tartan track stadium in late August 1982. Charles Rowell was a professional runner in Victorian times who ran a best distance of over 600 miles in a six day race held in "The Aggie" (Royal Agricultural Hall, Islington, London). The 1982 winner in Nottingham, Tom O'Reilly, ran 576 miles, that was 61 miles further than his nearest challenger, and numerous records were set, including world best times both for men and women at various ultradistances throughout the race.

Twenty-five competitors of age range 23 to 57 years (average age 41 years) commenced the race. Two of these were women, including the youngest competitor of 23 years of age who subsequently set a number of world records for women over various distances. One competitor was an experienced ultra walker. The winner's strategy was to run for periods of two to four hours, followed by a half hour's break. He usually took a recognised sleep period at the time he normally retired (approximately 5 hours) and chose to run at his own pace, ignoring the efforts of certain other runners who set world record times for certain distances. The leader after 24 hours had covered 135 miles, followed by the woman athlete who set a world record of 134 miles in a day. Ten athletes passed 100 miles at 24 hours, including the overall winner who was in ninth place at this time, (and who did not take the lead until the fourth day). Thereafter the winner's distances were:

$\begin{array}{cc}48 \text { hours } & 198 \text { miles } \\ 72 \text { hours } & 301 \text { miles } \\ 96 \text { hours } & 402 \text { miles } \\ 120 \text { hours } & 490 \text { miles } \\ 6 \text { days } & 576 \text { miles }\end{array}$

M. A. Hutson

(leader: 213 miles)

(leader: 314 miles)

His average weekly training distance in the previous six months was 120 miles a week, peaking 4 weeks prior to the event at 240 miles in that week. The training programmes for other athletes varied enormously; one athlete who completed $\mathbf{4 0 0}$ miles in this race felt that he did not wish to push himself to his full potential as he intended to pursue his weekly commitment of $\mathbf{2 5 0}$ miles the following week. Another competitor had prepared for the race by walking a 100 mile walk, a different endurance technique entirely and commenced the six day race with troublesome blisters.

As a result of experience in the USA the race directors had decided to change the direction of running every twelve hours in an attempt to reduce injuries, particularly in the inside leg. This did not indicate however that competitors rested from running equally during these twelve hour periods; most competitors had relatively lengthy rest (sleep) periods during the hours of darkness.

Thirteen athletes passed the $\mathbf{4 0 0}$ mile mark, including the $\mathbf{2 3}$ year old female and five males over $\mathbf{5 0}$ years of age. One competitor retired on the third day with bilateral Achilles tendinitis, the other twenty-four completing the course. Their average weight loss was 4 lbs (range +4 lbs--14 lbs).

\section{MEDICAL OBSERVATIONS}

Physiotherapy services were available at the site of the race and medical attention was also available on a number of occasions throughout each day. Records were kept of the injuries sustained and of the consultations with the doctor and physiotherapist. The number of competitors who sustained injuries sufficiently severe 
to impair their performance was 15 (60 per cent). Besides relatively minor complaints, such as muscle stiffness and blistering of feet, the principal injuries were:

Achilles tendinitis

No. of cases

Psoas bursitis

Tendinitis of the foot dorsiflexors

Patellar tendinitis

Patello-femoral syndrome

Gastrocnemius strain

Psychological stress

Gross tiredness/exhaustion

Shin splints (probably anterior

compartment syndrome)

Haemoglobinuria/haematuria
3 ( 1 severe)

8 (5 severe)

5 (1 severe)

2 (1 severe)

1 (severe)

2 (1 severe)

1

3

1

the race and not running at all for the last 24 hours, apart from a run-in at the finish.

The red blood cells and haemoglobin were found in the urine of the competitor who walked over $\mathbf{4 0 0}$ miles - he had previously suffered from frank blood stained urine and he was not too alarmed. Urinalysis was not routinely performed.

All of these injuries were stress related. Two of the competitors who developed Achilles tendinitis were unable to continue running. One retired from the race on the third day. The other continued to race by walking up to 50 miles a day for the last three days; the walking pattern was grossly abnormal, being a rotatory movement on heel strike with fixed ankle in an attempt to reduce calf contraction and Achilles stretch. Both had bilateral lesions with the development of fusiform swellings and associated peritendonitis - these signs developed as they continued to exercise after the onset of symptoms. It is a feature of the personality of long distance competitors of this calibre that injury does not prevent running unless severe; it is quite possible that tendinitis could extend under these circumstances to become partial rupture. It was interesting to note that as the race proceeded and the pace maintained the majority of competitors took some time after a rest to "loosen up" and reduce stiffness and initial pain. Occasionally, if the injury was not too severe, the symptoms would improve as the "training effect" of the race itself took effect. Only one competitor was thought to have a possible early stress fracture (of the tibia): symptoms did not worsen and may have been due to anserine bursitis rather than a stress fracture.

Of those competitors who suffered significant mental trauma, one had recently recovered from a tension illness and required reassurance after physical examination during the course of the race. The other developed rather paranoid feelings regarding his colleagues' views of possible drug taking, becoming very disenchanted with 